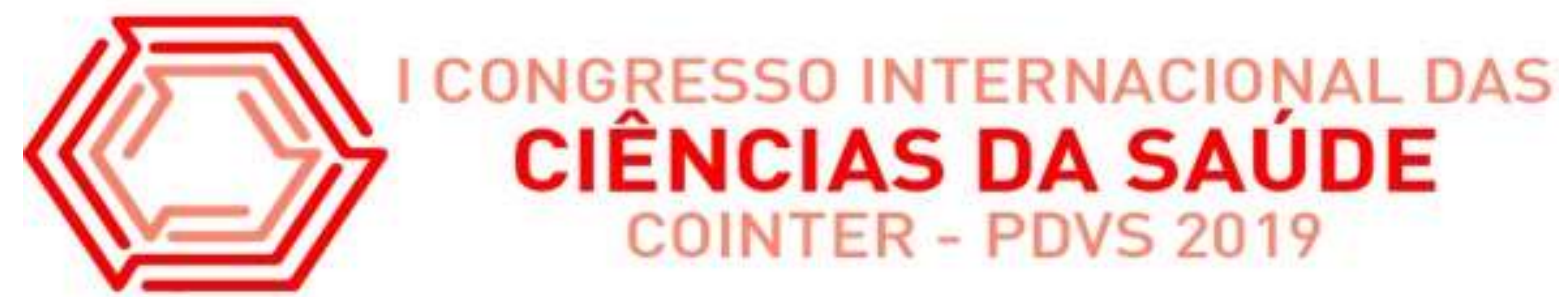

\title{
FORMIGAS COMO VETORES DE BACTÉRIAS E FUNGOS NO INTERIOR DE UM HOSPITAL DO SUL DA BAHIA
}

\section{HORMIGAS COMO VECTORES DE BACTERIAS Y HONGOS DENTRO DE UN HOSPITAL DEL SUR DE BAHIA}

\section{ANTS AS BACTERIA AND FUNGI VECTORS INSIDE A HOSPITAL IN SOUTH BAHIA}

\author{
Apresentação: Comunicação Oral
}

\begin{abstract}
Elivelton Melo Almeida ${ }^{1}$; Daiane Frelik Theodoro ${ }^{2}$, Cibelle Schuindt dos Santos Zetoles ${ }^{3}$; Sandra da Silva Silveira ${ }^{4}$; Renato Fontana ${ }^{5}$ DOI: https://doi.org/10.31692/ICOINTERPDVS.2019.0004
\end{abstract}

\begin{abstract}
Resumo
Infecções hospitalares, causadas principalmente por bactérias e fungos, constituem causa crescente de morbidade e mortalidade no Brasil e no mundo. Embora alguns insetos sejam vetores reconhecidos de microrganismos, as formigas têm-se revelado como ameaças à saúde pública, atuando como vetores mecânicos de microrganismos patogênicos. Assim, conhecer as espécies de formigas, bem como identificar as espécies de microrganismos que são encontrados e transportados por esses insetos, podem subsidiar ações educativas, complementando programas de prevenção e controle das infecções hospitalares. Foram realizadas coletas em diferentes setores de um hospital público da cidade de Itabuna nos meses de junho a agosto de 2009. Vinte e cinco formigas operárias foram coletadas. Também foi feita coleta, com o auxílio de um swab estéril, do local no qual os insetos foram retiradas. As formigas coletadas foram colocadas no interior de tubos estéreis, numeradas e imediatamente enviadas aos laboratórios de Mimercologia da CEPLAC para identificação e Microbiologia da UESC para processamento, o qual consistiu na inoculação de formigas inteiras em Ágar Sabouraud para crescimento fúngico e na separação das formigas em cabeça, tórax, abdome, patas e antenas, as quais foram colocadas individualmente em tubos com caldo BHI para crescimento bacteriano. Em seguida as bactérias foram inoculadas nos meios de

\footnotetext{
${ }^{1}$ Graduando do curso de Farmácia da Faculdade de Ciências Biomédicas de Cacoal - FACIMED. Email: eliveltomelo@hotmail.com

${ }^{2}$ Graduanda do curso de Farmácia da Faculdade de Ciências Biomédicas de Cacoal - FACIMED. Email: daianet-pb@hotmail.com

${ }^{3}$ Graduanda do curso de Farmácia da Faculdade de Ciências Biomédicas de Cacoal - FACIMED. Email: cibeleschuindt@gmail.com

${ }^{4}$ Biomédica Doutora em Ciências Biológicas e Docente na Faculdade de Ciências Biomédicas de Cacoal. Email:sandrass3@gmail.com

5 Biomédico doutor e Professor adjunto na Universidade Estadual de Santa Cruz - UESC. Email: rfontana@uesc.br
} 
cultura ágar sangue, ágar MacConkey e ágar Manitol para identificação. As bactérias foram classificadas microscopicamente pela coloração de Gram. Foram realizadas as provas bioquímicas para bactérias não fermentadoras e fermentadoras de açúcares. Em seguida, as formigas foram dispostas em tubos contendo Ágar Micosel para crescimento fúngico. Os fungos foram identificados segundos aspectos morfológicos da colônia bem como características morfológicas das estruturas microscópicas de reprodução, utilizando a técnica de microcultivo. Os gêneros bacterianos identificadas foram: Staphylococcus sp. e Bacillus sp. Os principais gêneros de fungos identificados foram Aspergillus sp., Cladosporium sp., Fusarium sp., Mucor sp., Paecilomyces sp., Rhizopus sp., e Rhodotorula sp., os quais estão amplamente envolvidos em infecções oportunistas. As espécies de formigas mais prevalentes foram Paratrechina longicornis, Pheydole megacephala, Solenopsis saevissima e Tapinoma melanocephalum. Assim, conhecer as espécies de formigas, bem como identificar as espécies de microrganismos que são encontrados e transportados por esses insetos, podem subsidiar ações educativas, complementando programas de prevenção e controle das infecções hospitalares.

Palavras-Chave: Pragas, Patógenos, imunodeficiência, Infecções.

\section{Resumen}

Las infecciones nosocomiales, principalmente causadas por bacterias y hongos, constituyen una causa creciente de morbilidad y mortalidad en Brasil y en todo el mundo. Aunque algunos insectos son vectores reconocidos de microorganismos, las hormigas han demostrado ser una amenaza para la salud pública, actuando como vectores de microorganismos patógenos. Por lo tanto, conocer las especies de hormigas, así como identificar las especies de microorganismos que estos insectos encuentran y transportan, puede apoyar acciones educativas, complementando los programas de prevención y control de infecciones nosocomiales. Se recolectaron muestras en diferentes sectores de un hospital público en la ciudad de Itabuna de junio a agosto de 2009. Se recogieron veinticinco hormigas obreras. También se recogió, con la ayuda de un hisopo estéril, del lugar donde se extrajeron los insectos. Las hormigas recolectadas se colocaron dentro de tubos estériles, se numeraron y se enviaron inmediatamente a los laboratorios de Mimercología de CEPLAC para su identificación y microbiología UESC para su procesamiento, que consistió en inocular hormigas enteras en agar Sabouraud para el crecimiento de hongos y separar las hormigas en cabeza, tórax, abdomen, patas y antenas, que se colocaron individualmente en tubos con caldo BHI para el crecimiento bacteriano. Luego las bacterias se inocularon en los medios de cultivo de agar sangre, agar MacConkey y agar de manitol para su identificación. Las bacterias se clasificaron microscópicamente por tinción de Gram. Se realizaron pruebas bioquímicas para bacterias no fermentadoras y fermentadoras de azúcar. Luego, las hormigas se colocaron en tubos que contenían agar Micosel para el crecimiento de hongos. Los hongos se identificaron según los aspectos morfológicos de la colonia, así como las características morfológicas de las estructuras de reproducción microscópica, utilizando la técnica de microcultivo. Los géneros bacterianos identificados fueron: Staphylococcus sp. y Bacillus sp. Los principales géneros de hongos identificados fueron Aspergillus sp., Cladosporium sp., Fusarium sp., Mucor sp., Paecilomyces sp., Rhizopus sp. Y Rhodotorula sp., Que están ampliamente involucrados en infecciones oportunistas. Las especies de hormigas más prevalentes fueron Paratrechina longicornis, Pheydole megacephala, Solenopsis saevissima y Tapinoma melanocephalum. Por lo tanto, conocer las especies de hormigas, así como identificar las especies de 
microorganismos que estos insectos encuentran y transportan, puede apoyar acciones educativas, complementando los programas de prevención y control de infecciones nosocomiales.

Palabras Clave: Plagas, Patógenos, Immunodeficiencia, Infecciones.

\begin{abstract}
Nosocomial infections, mainly caused by bacteria and fungi, constitute a growing cause of morbidity and mortality in Brazil and worldwide. Although some insects are recognized vectors of microorganisms, ants have proved to be a threat to public health, acting as vectors of pathogenic microorganisms. Thus, knowing the species of ants, as well as identifying the species of microorganisms that are found and transported by these insects, can support educational actions, complementing programs for prevention and control of nosocomial infections. Samples were collected in different sectors of a public hospital in the city of Itabuna from June to August 2009. Twenty-five worker ants were collected. It was also collected, with the aid of a sterile swab, from the place where the insects were removed. The collected ants were placed inside sterile tubes, numbered and immediately sent to CEPLAC's Mimercology laboratories for identification and UESC Microbiology for processing, which consisted of inoculating whole ants on Sabouraud Agar for fungal growth and separating the ants into head, thorax, abdomen, paws and antennae, which were placed individually in tubes with BHI broth for bacterial growth. Next the bacteria were inoculated into the blood agar, MacConkey agar and Mannitol agar culture media for identification. The bacteria were classified microscopically by Gram stain. Biochemical tests were performed for nonfermenting and sugar fermenting bacteria. Then the ants were placed in tubes containing Micosel Agar for fungal growth. The fungi were identified according to morphological aspects of the colony as well as morphological characteristics of the microscopic reproduction structures, using the microculture technique. The identified bacterial genera were: Staphylococcus sp. and Bacillus sp. The main genera of fungi identified were Aspergillus $s p$., Cladosporium sp., Fusarium sp., Mucor sp., Paecilomyces sp., Rhizopus sp., And Rhodotorula sp., Which are widely involved in opportunistic infections. The most prevalent ant species were Paratrechina longicornis, Pheydole megacephala, Solenopsis saevissima and Tapinoma melanocephalum. Thus, knowing the species of ants, as well as identifying the species of microorganisms that are found and transported by these insects, can support educational actions, complementing programs for prevention and control of nosocomial infections.
\end{abstract}

Keywords: Pests, Pathogens, Immumodeficiency, Infections.

\title{
Introdução
}

Atualmente, existem mais de 100.000 espécies de fungos formalmente descritas, embora menos de 100 estejam rotineiramente associados a doenças humanas. ${ }^{1,2}$ Os fungos são encontrados em uma variedade de habitats, mas sua presença pode ser potencialmente 
prejudicial quando ocorrendo em ambientes associados a humanos, como hospitais. A ocorrência de fungos em áreas hospitalares tem sido relatada em vários países, incluindo o Brasil. $^{3,4}$ Os filamentosos onipresentes gêneros fúngicos Aspergillus, Cladosporium, Curvularia, Fusarium, Penicillium e o gênero levedura Candida são rotineiramente encontrados em vários departamentos hospitalares. Tais fungos são considerado não patogênico, mas quando ocorre no ambiente hospitalar podem estar associados a várias micotoxicoses, como infecções no ouvido, trato urinário, unhas, infecções oculares, e fungemias. ${ }^{3,4}$

Nos últimos anos, tem havido um grande aumento no número de infecções causadas por fungos anteriormente considerados não patogênicos. ${ }^{1,4}$ Essas infecções são frequentemente associadas à imunodeficiência que ocorre em pacientes com câncer, HIV/AIDS e naqueles recebendo tratamento imunossupressor. ${ }^{3 \mathrm{e} 5}$ Os fungos desempenham um papel importante nas infecções nosocomiais, algumas graves e até fatais. ${ }^{3,4} \mathrm{~A}$ identificação de fontes putativas de fungos nos vários departamentos hospitalares é de grande importância para profissionais de saúde e para pacientes que frequentam o ambiente hospitalar ou permanecem nesses locais. As principais rotas de fungos transmissão são através de poeira, aerossóis, fontes ambientais (solo e vegetação), fomitos e vetores, como insetos. ${ }^{3,5,6}$

Vários autores abordaram o papel específico dos insetos encontrados em hospitais como portadores de microrganismos associados com infecções nosocomiais. ${ }^{7,8}$ Bactérias também desempenham um papel importante na ocorrência de infecções hospitalares. Bactérias gram-negativas como a Escherichia coli representam uma grande ameaça a saúde de pacientes nosocomiais.Tanaka et al (2007) encontrou colonização de bactérias grampositivas e gram-negativas em formigas das espécies Tapinoma melanocephalum e Paratrechina longicornis. As espécies encontradas foram do gênero Corinebacterium, Klebsiella e E. colli.

O papel das formigas como portadoras de microrganismos nos hospitais tem sido objeto de crescente interesse, principalmente no Brasil, mas também em alguns países do hemisfério norte. ${ }^{9 \mathrm{e} 11}$ Vários estudos mostraram que formigas encontradas em hospitais se tornam um sério problema de saúde pública, atuando como vetores quando transportando microrganismos patogênicos. ${ }^{11 \mathrm{e} 13} \mathrm{~A}$ maioria dessas formigas são invasivos e bem adaptados aos ambientes humanos, aninhando na estrutura ou nos móveis do hospital e forrageando quase todo o edifício. ${ }^{9,11,14}$ Enquanto uma única formiga ocasionalmente foi relatada em 
hospitais em muitos países temperados, várias espécies (variando de quatro a 23 espécies de acordo com Fontana et al.) podem infestar simultaneamente muitas unidades em hospitais brasileiros, incluindo a terapia intensiva (UTI), enfermaria, enfermaria, hemodiálise, quimioterapia centros de oncologia, endoscopia, refeitório, apartamentos e setores da cama, etc. $^{6,11,14}$. Observações casuais relatam atividade das formigas em material estéril, lixo hospitalar ou até curativos de pacientes em hospitais brasileiros. ${ }^{9,14}$

Embora se saiba muito sobre a dispersão bacteriana por formigas em hospitais, há pouca informação sobre a natureza e diversidade de fungos transportados por esses insetos nas diversas localizações hospitalares. ${ }^{10,11,13} \mathrm{O}$ objetivo deste estudo foi avaliar a composição de espécies de fungos e bactérias encontrada nas partes externas de formigas em um hospital no sul da Bahia (nordeste do Brasil).

\section{Metodologia}

Amostras de formigas

O estudo foi realizado em um hospital e maternidade público na cidade de Itabuna, estado da Bahia, nordeste do Brasil. Em uma pesquisa de um ano (2009e2010) o hospital foi visitado onze vezes para a amostragem de formigas. Doze setores do hospital foram selecionados e amostrados em cada visita: banco de leite materno, capela, área de utilidade suja (uma área de espera para resíduos e linho usado), leitos hospitalares, maternidade, UTI neonatal, creche, oncologia, dois departamentos pediátricos, radioterapia e restaurante. Embora houvesse suspeita de numerosos casos clínicos de doenças fúngicas no hospital, não havia documentação formal disponível no momento. A amostragem em todas as áreas do hospital foi realizada durante o durante o dia e a preferência foi dada aos locais onde era possível observar formigas ativamente forrageadoras. Os trabalhadores foram colecionados usando folhas de papel estéreis e fórceps seguindo procedimentos anteriormente descritos..$^{9,11}$ Resumidamente, os trabalhadores foram removido do chão usando uma folha de papel estéril e imediatamente transferido para tubos de vidro estéreis usando fórceps. ${ }^{9,11}$ Alguns autores usam iscas como atrativos para amostragem de formigas, mas este método não foi utilizado no presente estudo, uma vez que Os trabalhadores eram sempre fáceis de localizar, e a intenção era evitar introduzir no experimento outras fontes de fungos, causando contaminação. ${ }^{15}$

\section{Isolamento e identificação de fungos}


Formigas foram identificadas pela primeira vez no Laboratório de Myrmecology (CEPLACeCEPEC, Coleção CPDC). Após a identificação, as formigas foram transferidas para o Laboratório de Microbiologia Universidade Estadual de Santa Cruz (UESC) para isolamento de fungos. Todo o procedimento de coleta de formigas, identificação e fungos a cultura foi realizada no mesmo dia. Quanto ao isolamento e identificação de fungos, estudamos fungos isolados das partes externas de formigas operárias capturadas. As formigas vivas foram transferidas para Ágar Mycosel (Becton Dickinson, Franklin Lakes, NJ, EUA) encostas (uma inclinação por trabalhador) usando uma pinça estéril e incubada por sete dias a 27 C no escuro. Após a incubação, as encostas foram rastreadas quanto a qualquer crescimento fúngico. Colônias de fungos foram subcultivados em placas com Agar de Dextrose de Batata (PDA; Becton Dickinson) até serem obtidas culturas puras. Todos os isolados são mantidos em inclinações de PDA a $4 \mathrm{C}$ no Laboratório de Microbiologia (Universidade Estadual de Santa Cruz). Os isolados fúngicos foram identificados utilizandose marcadores. A morfologia geral da colônia, bem como a características microscópicas das estruturas reprodutivas foi usado para identificá-los. 16 Marcadores microscópicos examinados usando culturas de lâminas coradas com lactofenol como o líquido de montagem. Geral e específico chaves taxonômicas foram utilizadas para identificação. ${ }^{16,20}$

\section{Resultados e Discussão}

Foram identificadas 12 espécies de formigas no HMMN (Tabela 1). As espécies de formigas identificadas foram Tapinoma melanocephalum (30,6\%), Paratrechina longicornis (18,0\%), Pheydole megacephala (15,4\%), Solenopsis saevissima (11,5\%), Tetramorium simillimum (10,4\%), Cremalogaster sp. (7,7\%), Wasmannia auropunctata (1,9\%), Acromymex balzani (0,9\%), Camponotus crassus (0,9\%), Camponotus vitattus (0,9\%), Cyphomyrmex rimosus (0,9\%) e Ectatomma brunneum (0,9\%).

Tabela 1 - Frequência relativa e absoluta de espécies de formigas coletadas em um hospital da cidade de Itabuna-BA.

\begin{tabular}{|l|c|c|}
\hline \multicolumn{1}{|c|}{$\begin{array}{c}\text { Espécies de } \\
\text { formiga }\end{array}$} & $\begin{array}{c}\text { Frequência } \\
\text { Absoluta }\end{array}$ & $\begin{array}{c}\text { Frequência } \\
\text { Relativa (\%) }\end{array}$ \\
\hline T. melanocephalum & 32 & 30,6 \\
\hline P. longicornis & 19 & 18,0 \\
\hline P. megacephala & 16 & 15,4 \\
\hline S. saevissima & 12 & 11,5 \\
\hline
\end{tabular}




\begin{tabular}{|l|c|c|}
\hline T. simillimum & 11 & 10,4 \\
\hline Cremalogaster $\mathrm{sp}$. & 8 & 7,7 \\
\hline W. auropunctata & 2 & 1,9 \\
\hline A. balzani & 1 & 0,9 \\
\hline C. crassus & 1 & 0,9 \\
\hline C. vitattus & 1 & 0,9 \\
\hline C. rimosus & 1 & 0,9 \\
\hline E. brunneum & 1 & 0,9 \\
\hline \multicolumn{1}{|c|}{ Total } & $\mathbf{1 0 5}$ & $\mathbf{1 0 0}$ \\
\hline
\end{tabular}

Foram identificados 13 gêneros de fungos: Acremonium sp., Alternaria sp., Aspergillus sp., Cladosporium sp., Cunninghamella sp., Fusarium sp., Mucor sp., Paecilomyces sp., Penicillium sp., Rhizopus sp., e Rhodotorula sp., Scolecobabidium sp. e Verticillium sp. Algumas espécies fúngicas que puderam ser identificadas foram Aspergillus flavus, Cunninghamella echinulata e Fusarium solani (Figura1).

As espécies Tapinoma melanocephalum, Paratrechina longicornis e Pheydole megacephala foram as que apresentaram maior diversidade de fungos seguida da Solenopsis saevissima. Os setores hospitalares que apresentaram a maior diversidade de fungos foram Leitos, Berçário, Banco de Leite e Pediatria SUS (Tabela2).

Tabela 2 - Fungos isoladas das espécies de formigas coletadas de um hospital público de Itabuna-BA.

\begin{tabular}{|c|c|c|}
\hline Espécies de Formigas & Espécies de Fungos & Local da Coleta \\
\hline T. melanocephalum & $\begin{array}{lr}\text { Mucor } \text { sp., } & \\
\text { Acremonium } & \text { sp., } \\
\text { Paecilomyces } & \text { sp., } \\
\text { Aspergillus sp., } & \\
\text { Fusarium } & \text { Solani, } \\
\text { Cladosporium sp. } & \end{array}$ & $\begin{array}{l}1,2 \\
6 \\
12 \\
1,11 \\
11 \\
13\end{array}$ \\
\hline P. longicornis & $\begin{array}{l}\text { Mucor } \mathrm{sp} . \\
\text { Fusarium } \mathrm{sp} . \\
\text { Aspergillus } \mathrm{sp} . \\
\text { Rizhopus } \mathrm{sp} . \\
\text { Paecilomyces } \\
\text { Cladosporium } \mathrm{sp} .\end{array}$ & $\begin{array}{l}1,2 \\
1 \\
1 \\
1 \\
10 \\
10\end{array}$ \\
\hline P. megacephala & $\begin{array}{l}\text { Paecilomyces sp. } \\
\text { Cladosporium sp. }\end{array}$ & $\begin{array}{l}4, \\
4,3,5,13\end{array}$ \\
\hline
\end{tabular}




\begin{tabular}{|l|l|l|}
\hline & Verticillium sp. & 8 \\
& Rhodotorula sp. & 8,9 \\
& Alternaria sp. & 3 \\
& Aspergillus flavus & 11 \\
\hline S. saevissima & $\begin{array}{l}\text { Cunninghamella sp. } \\
\text { Penicillium sp. } \\
\text { Aspergillus } \\
\text { Cunninghamella echinulata }\end{array}$ & 5 \\
& & 5 \\
\hline T. simillimum & Fusarium sp. & 11 \\
& Aspergillus flavus & 13 \\
\hline Cremalogaster sp. & Scolecobabidium & 10 \\
& Paecilomyces sp. & 3 \\
\hline W.auropunctata & Scolecobabidium sp. & 11 \\
\hline C. vitattus & Aspergillus flavus & 9 \\
\hline C. rimosus & Aspergillus flavus & 10 \\
\hline
\end{tabular}

Setores: 1- Leitos, 2- UTI Neonatal, 3- Oncologia, 4- Lixo, 5- Banco de Leite, 6- Expurgo de Lixo, 7Maternidade, 8- Capela, 9- Pediatria, 10- Pediatria SUS, 11- Berçário, 12- Refeitório, 13Radioterapia.

Foram identificadas 12 espécies de formigas no HMMN, sendo que as espécies mais prevalentes foram Tapinoma melanocephalum, Paratrechina longicornis e Pheydole megacephala. LISE et al (2006) descrevem as formigas Monomorium pharaonis e Solenopsis saevissima como espécies mais freqüentes encontrados em hospitais de Santa Catarina, já BICHO et al (2007) descrevem os gêneros Acromyrmex lundi, Brachymyrmex sp. e Camponotus sp como mais freqüentes em hospitais e postos de saúde do município de Bagé no Rio Grande do Sul.

Foram identificados 13 gêneros de fungos, dos quais Aspergillus sp., Paecilomyces sp., Cladosporium sp. e Fusarium sp., foram os gêneros mais freqüentes, sendo o Aspergillus sp. o principal. Os resultados obtidos neste trabalho são similares aos encontrados por CARMO (2007), que pesquisando a Microbiota fúngica dos setores de um hospital público em Campina Grande - PB, observou a presença de Cladosporium sp., entre os quatro fungos mais isolados em suas dependências. LOYOLA (2008) mostrou que a infecção por Aspergillus sp em pacientes imunossuprimidos apresenta taxa de mortalidade em torno de $86 \%$, independente do tratamento antifúngico e infecções por Fusarium sp são altamente 
resistentes à terapia disponível, com prognostico desfavorável e taxa de mortalidade em torno de $57 \%$ dos casos.

O setor mais contaminado foi o dos leitos. Esse resultado é bastante preocupante, tendo em vista que é nesse setor que os pacientes ficam acomodados a maior parte do seu tempo de permanência no hospital. A contaminação observada em todos os setores pode ser associada com o fluxo humano, falta de metodologia de limpeza, uma provável baixa eficiência dos desinfetantes utilizados. Alem de outros fatores que contribuem para a permanência ou penetração de microrganismos como ventilação, temperatura e a umidade ambiental, entre outros. ${ }^{33,36}$. Alguns gêneros dos fungos isolados nos diferentes setores do ambiente hospitalar podem estar associados a quadros de micoses oportunísticas, que são infecções causadas por fungos de baixa virulência, que convivem pacificamente com o hospedeiro, mas que, ao encontrarem condições favoráveis, desenvolvem seu poder patogênico. As micoses oportunísticas podem estar associadas a fatores intrínsecos ao hospedeiro (neoplasias, diabetes, dentre outras, bem como todas as doenças que alteram a imunidade celular) ou fatores extrínsecos (antibioticoterapia, corticoidoterapia, etc.). ${ }^{37} \mathrm{~A}$ única exceção foi o fungo Verticillium sp. sendo um gênero envolvido com doenças em plantas.

É possível associar as formigas aos fungos devido ao ambiente explorado por estes insetos, que coincide com as condições físico-químicas propícias para a proliferação destes microrganismos. Estas condições são, muitas vezes, criadas pelas formigas de forma a conseguir benefícios desta associação, oferecendo situação propícia para a proliferação de fungos de modo geral, devido à semelhança da biologia destes microrganismos. ${ }^{37}$

A diversidade de espécies de formigas encontradas neste estudo é comparável ao que foi observado em estudos anteriores que relataram um intervalo de uma a 23 espécies. ${ }^{6,11,14,22}$ T. melanocephalum e P. longicornis foram as espécies de formigas mais comuns sete e seis dos 12 setores hospitalares, respectivamente. Estas formigas espécies foram relatadas anteriormente ocorrendo em hospitais e parecem ser habitantes comuns de tais ambientes. ${ }^{6,9,11}$ O berçário, pediatria ( 1 e 2) e oncologia, contendo pacientes de alto risco, foram os locais com maior número de espécies de formigas. Em particular, a creche e pediatria são ocupados por bebês e crianças que não possuem sistema imunológico desenvolvido. O número de espécies de formigas identificadas nessas áreas críticas podem ser explicadas pelo trânsito de um elevado número de pessoas, a quantidade de alimentos encontrado por formigas 
forrageiras, a baixa qualidade de higiene, bem como controle efetivo desses insetos. Esses fatores também podem ser considerados para os achados no banco de leite materno e áreas de utilidade. Apesar da frequência com que esses insetos foram encontrados nas áreas amostradas, apenas duas espécies de formigas foram identificadas nos leitos hospitalares, UTI neonatal e maternidade (Tabelas I).

Embora várias espécies de formigas sejam bem conhecidas por serem abundantes em ambientes hospitalares, a probabilidade de uma operária portar um potencial microrganismo causador de doenças é relativamente baixo, mas é aumentado por três características preponderantes da biologia da formiga: (i) sua vida social, na qual os indivíduos estão em contato próximo, facilitando a disseminação de tais microorganismos entre trabalhadores; (ii) a alta estabilidade dos formigueiros ao longo do tempo, tornando tais estruturas uma fonte permanente de contaminação por esses microrganismos; (iii) o ativo e contínua forrageamento e exploração de seu meio ambiente formigas. ${ }^{9,} 12$ Além disso, o número de formigas com filamentos os fungos encontrados neste estudo (Tabelas I e II) e a número de formigas portadoras de bactérias encontradas em estudos anteriores mostram que a alta frequência de ocorrência de formigas em hospitais multiplica essa probabilidade, já que a probabilidade de uma formiga ser infectado por bactérias pode atingir até $98 \% .9,11,23$. No hospital de Itabuna $40 \%$ das formigas foram contaminadas com fungos (Tabela I) e pelo menos 10 diferentes taxas de fungos foram associados com T. melanocephalum, P. longicornis e P. Megacephala (Tabela II). Essas espécies de formigas foram descritas por vários autores como os principais portadores de bactérias nos hospitais. ${ }^{9,12,15}$ Durante os períodos de amostragem, nenhuma formiga observado forrageamento em corpos de pacientes ou leitos. Contudo, observações anteriores mostraram que essas formigas podem usar locais para forrageamento (R. Fontana et al., observação pessoal) em a qualquer hora do dia, ou à noite, desde algumas formigas (gênero Camponotus, por exemplo) são essencialmente noturnos.

$\mathrm{O}$ isolamento de fungos bacterianos e oportunistas de formigas em ambientes hospitalares data da década de 1980. ${ }^{1,9,14,21}$ no hospital onde este estudo foi realizado, não existe um programa efetivo de monitoramento e controle infecções fungais. A implementação de um programa para coletar amostras não é uma tarefa fácil, já que envolve trabalho complementar de vários grupos independentes no hospital. Por outro lado, o monitoramento promoveria a procedimentos de controle, manutenção, limpeza e desinfecção bem como a conscientização desses procedimentos de saúde pelos profissionais. ${ }^{4,11,24,29}$ Nos países 
tropicais, temperatura e umidade estimula a proliferação de diversos consórcios fúngicos em todos os lugares em ambientes associados a humanos, mesmo se vários doenças causadas por fungos patogênicos bem conhecidos são reconhecidas como tendo como substratos de reservatório presentes no meio Ambiente. Assim, a ocorrência de tal micobiota em áreas hospitalares significa que as formigas agem como portadores de filamentos aerotransportados fungos e leveduras e pode, portanto, representar risco potencial para pacientes hospitalizados. ${ }^{11,13,15}$ Em geral, a falta de casos clínicos de infecção por fungos no ar, como aqueles encontrados associados às formigas, não nos permitem correlacionar casos com qualquer ocorrência de fungos no hospital e maternidade público de Itabuna. 


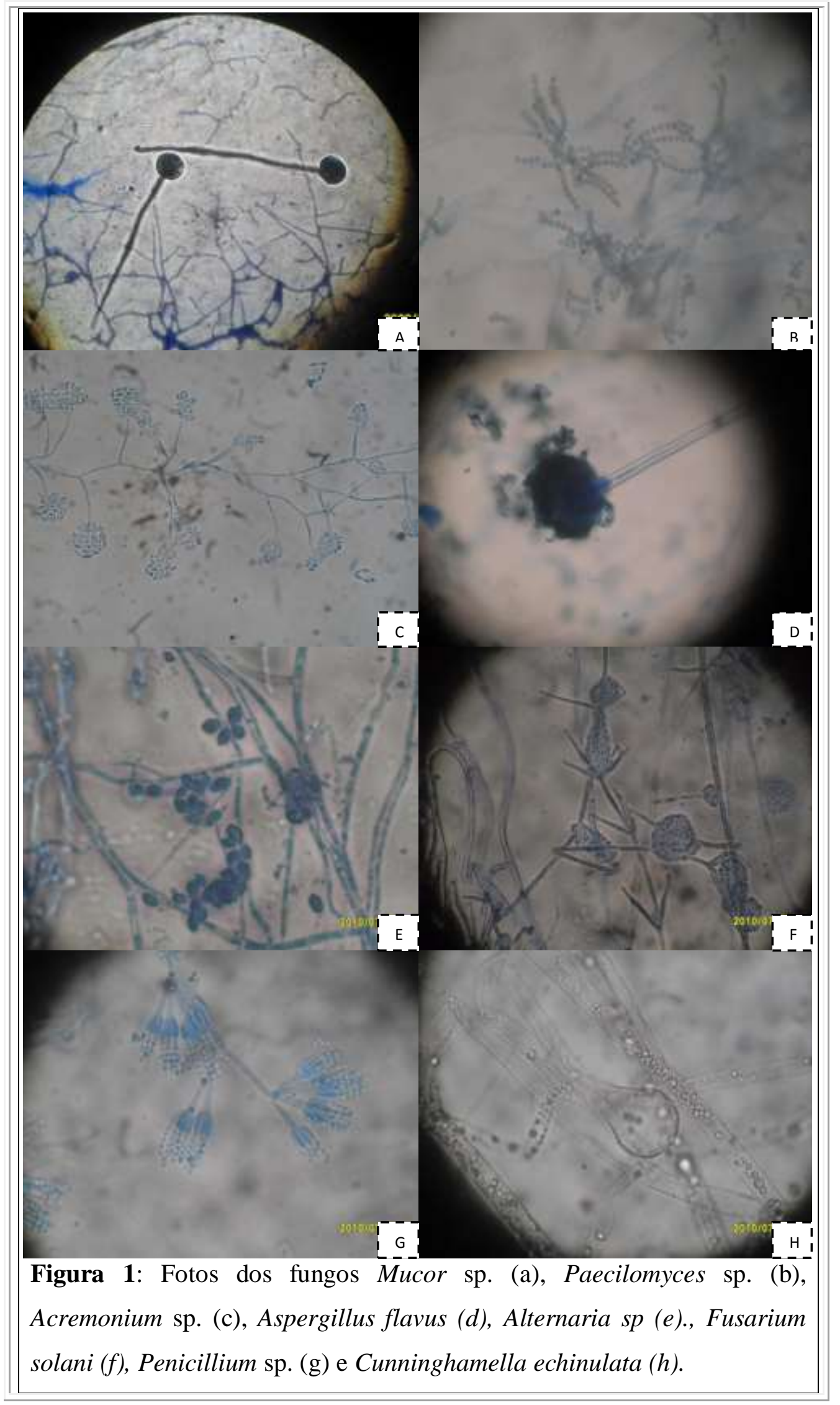




\section{Conclusões}

Nos setores pesquisados, os fungos de maior freqüência de isolamento foram Aspergillus sp., Paecilomyces sp., Cladosporium sp. e Fusarium sp.. Prevalecendo dentre todos o Aspergillus sp. A transmissão pelo ar é uma considerável fonte de infecções fúngicas. Sabe-se que o tratamento destas em pacientes imunodeprimidos é difícil e que estas infecções são geralmente fatais. A prevenção vem ser a melhor medida de controle e, portanto conhecer a epidemiologia do ambiente hospitalar vem ser crucial no desenvolvimento de estratégias preventivas.

Pode-se justificar a grande diversidade fúngica encontrada no HMMN no fato desse hospital ser situado numa região de clima transitório quente e úmido, ou seja, onde as condições de clima, umidade e temperatura favorecem o desenvolvimento de fungos.

Sugere-se que sejam implantados medidas de higiene e limpeza mais eficazes, melhorando assim a qualidade do ambiente hospitalar.

Assim, conhecer as espécies de formigas, bem como identificar as espécies de microrganismos que são encontrados e transportados por esses insetos, podem subsidiar ações educativas, complementando programas de prevenção e controle das infecções hospitalares.

\section{Referências}

1. PERDELLI F, CRISTINA ML, SARTINI M, et al. Fungal contamination in hospital environments. Infect Control Hosp Epidemiol 2006; 27:44e47.

2. BLACKWELL M. The fungi: 1, 2, 3 . 5.1 million species? Am J Bot 2011;98:426e438.

3. CARMO ES, BELEM LF, CATA ${ }^{\sim} \mathrm{RM}$, et al. Microbiota fúngica presente em diversos setores de um hospital público em Campina Grande- PB. RBAC 2007;39:213e216.

4. FAURE O, FRICKER-HIDALGO H, LEBEAU MR, et al. Eight-year surveillance of environmental fungal contamination in hospital operating rooms and haematological units. J Hosp Infect 2002;50:155e160.

5. MENEZES EA, ALCANFOR AC, CUNHA FA. Fungos anemófilos na sala de perio'dicos da biblioteca de cie^ncias da sau'de da Universidade Federal do Ceara'. RBAC 2006;38:155e158.

6. COSTA SB, PELLI A, CARVALHO GP, et al. Ants as mechanical vectors of microorganisms in the School Hospital of the Universidade Federal do Trianngulo Mineiro. Rev Soc Bras Med Trop 2006;39:527e529.

7. DANIEL M, SRA'MOVA' H, ZA`LABSBA' E. Lucilia sericata (Diptera: Calliphoridae) causing hospital-acquired myiasis of a traumatic wound. J Hosp Infect 1994;28:149e152.

8. FOTEDAR R, BANERJEE U, VERMA AK. Cockroaches (Blattella germanica) as carrier of microorganisms of medical importance in hospital. Epidemiol Infect 
1991;107:181e187.

9. FOWLER HG, BUENO OC, SADATSUNE T, MONTELLI AC. Ants as potential vectors of pathogens in Brazil hospitals in the State of Sa o Paulo, Brazil. Insecta Sci Appl 1993;14:367e370.

10. MOREIRA DDO, MORAIS V, VIEIRA-DA-MOTA O, et al. Ants as carriers of antibiotic-resistant bacteria in hospitals. Neotrop Entomol 2005;34:999e1006.

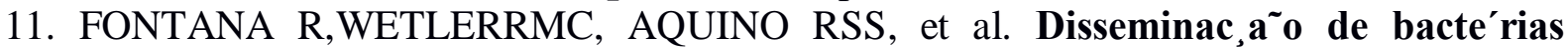
patoge^nicas por formigas (Hymenoptera: Formicidae) em dois hospitais do Nordeste do Brasil. Neotrop Entomol 2010;39:655e663.

12. BEATSON SH. Pharaoh's ants as pathogens vectors in hospitals. Lancet $1972 ; 1: 425 \mathrm{e} 427$.

13. RODOVALHO CM, SANTOS AL, MARCOLINO MT, BONETTI AM, BRANDEBURGO MAM. Urban ants and transportation of nosocomial bacteria. Neotrop Entomol 2007;36:454e458.

14. EICHELER W. Health aspects and control of Monomorium pharaonis. In: Vander Meer RK, Jaffe K, Cedeño A, editors. Applied myrmecology: a world perspective. Boulder, CO: Westview Press; 1990. p. 671e675.

15. PANTOJA LDM, MOREIRA FILHO RE, BRITO EHS, et al. Ants (Hymenoptera, Formicidae) as carriers of fungi in hospital environments: an emphasis on the genera Tapinoma and Pheidole. J Med Entomol 2009;46:895e899.

16. DE HOOG GS, GUARRO J, GENE' J, FIGUERAS MJ. Atlas of clinical fungi. Centraalbureau voor Schimmelcultures. Utrecht/Reus: Universitat Rovira I Virgilli; 2000.

17. DOMSCH KH, GAMS W, ANDERSON TH. Compendium of soil fungi. New York: Academic Press; 1980.

18. PITT JI. A laboratory guide to common Penicillium species. North Ryde: Food Science Australia; 2000.

19. LIU XY, HUANG H, ZHENG RY. Relationships within Cunninghamella based on sequence analysis of ITS rDNA. Mycotaxon 2011; 80:77e95.

20. KLICH MA. Identification of common Aspergillus species. Baarn: Centraalbureau voor Schimmelcultures; 2002.

21. IPINZA-REGALA J, FIGUEROA JG, OSO`RIO J. Iridomyrmex humilis, "formiga argentina", como vector de infecciones intrahospitalares. I e Estudio bacteriologico. Folia Entomol Mex 1981;50:81e96.

22. DELABIE JH, FONTANA R, BRITO TA, FERREIRA SL. Infecc, $\mathbf{a}^{\sim}$ hospitalar e formigas no Brasil: o caso de um hospital do sudeste da Bahia. O Bioló'gico 2002;64:41e42.

23. PEREIRA RS, UENO M. Formigas como veiculadoras de microrganismos em ambiente hospitalar. Rev Soc Bras Med Trop 2008;41:492e495.

24. PANAGOPOULOU P, FILIOTI J, PETRIKKOS G. Environmental surveillance of filamentous fungi in three tertiary care hospitals in Greece. $J$ Hosp Infect 2002;52:185e191.

25. DIAS-GUERRA TM, MELLADO E, CUENCA-ESTRELLA M, et al. Genetic similarity among one Aspergillus flavus strain isolated from a patient who underwent heart surgery in two environmental strains obtained from the operating room. J Clin Microbiol 2000;38:2419e2422.

26. CORNET M, LEVY V, FLEURY L, et al. Efficacy of prevention by highefficiency particulate air filtration or laminar airflow against Aspergillus airbone contamination during hospital renovation. Infect Control Hosp Epidemiol 1999;20:508e513. 
27. LOPES JO, ROLLING LC, NEUMAIER W. Kerionlike lesion of the scalp due to Acremonium kiliense in a noncompromissed boy. Rev Inst Med Trop $S$ Paulo 1995;37:365e368.

28. SCOLAN V, TELMON N, ROUGE JC, ROUGE D. Responsabilite' me'dicale et infections nosocomiales. Rev Med Interne 2000;21:361e367.

29. PANAGOPOULOU P, FILIOTI J, FARMAKI E, et al. Filamentous fungi in a tertiary care hospital: environmental surveillance and susceptibility to antifungal drugs. Infect Control Hosp Epidemiol 2007;28:60e67.

30. BICHO, C. L.; BRANCÃO, M. L. C.; PIRES, S. M. Mirmecofauna (hymenoptera, formicidae) em hospitais e Postos de saúde no município de bagé, rs. Arq. Inst. Biol., São Paulo, v.74, n.4, p.373-377, out./dez, 2007.

31. CARMO, e. s.; BELÉM, 1. f.; CATÃO, R. M. R.; LIMA, E. O.; SILVEIRA, I. L.; SOARES, L. H. M. Microbiota fúngica presente em diversos setores de um hospital público em Campina Grande - PB. RBAC, vol. 39(3): 213-216, 2007.

32. Costa, S. B.; PElli, A.; CARVAlho, G. P,; Oliveira, A. G.; SIlva, P. R.;TEIXEIRA, M. M.; MARTINS, E.; TERRA, A. P. S.; RESENDE, E. M.; OLIVEIRA, C. C. H. B.; MORAIS, C. A. Formigas como Vetores Mecânicos de Microorganismos no Hospital Escola da Universidade Federal do Triângulo Mineiro. Revista da Sociedade Brasileira de Medicina Tropical, 39 (6): 527-529 2006.

33. LACAZ, C. S. Infecções por Agentes Oportunistas. São Paulo: Edgar Beucher, 1977.

34. LISE, F.; GARCIA, F. R. M.; LUTINSKI, J. A. Associação entre formigas (Hymenoptera: Formicidae) e bactérias em hospitais de Santa Catarina. Rev. Soc. Bras. Med. Trop. vol.39 no.6 Uberaba Nov./Dec. 2006.

35. LOYOLA, A. B. A. T. Avaliação da suscetibilidade de Aspergillus spp e Fusarium spp a antifungicos por microdiluição em caldo e sistema de monitorização de cresfimento de hifas (Biocell-tracer $\left.{ }^{\circledR}\right)$. Universidade Estadual de Campinas. Faculdade de Ciências Médicas. Tese (doutorado). 2005.

36. SILVA, M. G. Flora fúngica do ar e do piso no hospital das clínicas da UFMG, Belo Horizonte, Brasil, Rev. Microbial., São Paulo: 14(3): 215-222, Jul/Set, 1983.

37. TRABULSI, Luiz Rachid. Microbiologia. 3. ed. São Paulo: Atheneu, 1999. 